\title{
Article
}

\section{Sensitive and easily recyclable plasmonic SERS substrate based on Ag nanowires in mesoporous silica}

Yan, Xuefeng, Wang, Lingzhi, Qi, Dianyu, Lei, Juying, Shen, Bin, Sen, Tapas and Zhang, Jinlong

Available at http://clok.uclan.ac.uk/13683/

Yan, Xuefeng, Wang, Lingzhi, Qi, Dianyu, Lei, Juying, Shen, Bin, Sen, Tapas ORCID: 0000-0002-0463-7485 and Zhang, Jinlong (2014) Sensitive and easily recyclable plasmonic SERS substrate based on Ag nanowires in mesoporous silica. RSC Adv., 4 (101). pp. 57743-57748. ISSN 2046-2069

It is advisable to refer to the publisher's version if you intend to cite from the work. http://dx.doi.org/10.1039/c4ra09170a

For more information about UCLan's research in this area go to http://www.uclan.ac.uk/researchgroups/ and search for <name of research Group>.

For information about Research generally at UCLan please go to http://www.uclan.ac.uk/research/

All outputs in CLoK are protected by Intellectual Property Rights law, including Copyright law. Copyright, IPR and Moral Rights for the works on this site are retained by the individual authors and/or other copyright owners. Terms and conditions for use of this material are defined in the policies page.

\section{CLoK}

Central Lancashire online Knowledge www.clok.uclan.ac.uk

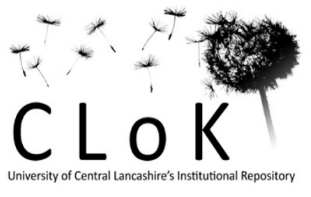




\section{Sensitive and Easily Recyclable Plasmonic SERS Substrate based on Ag Nanowire in Mesoporous Silica}

Xuefeng Yan, Lingzhi Wang*, Dianyu Qi, Juying Lei, Bin Shen Sen Tapas* and Jinlong Zhang*

\section{Experimental Section}

\section{Chemicals:}

Tetraethylorthosilicate (TEOS), n-Hexane, Potassium chloride $(\mathrm{KCl})$ were purchased from Shanghai Lingfeng Chemical Reagent Co. Ltd without further purification. Silver nitrate $(\mathrm{AgNO} 3)$ and $\mathrm{FeCl} 3 \cdot 6 \mathrm{H} 2 \mathrm{O}$ was purchased from Shanghai Chemical Reagent. Poly (ethylene glycol)-block-poly(propylene glycol)-block-poly(ethylene glycol) (P123) was purchased from Sigma-Aldrich. Ultrapure water (=18.0 M $\Omega$ ) purified using the Milipore Milli-Q gradient system

\section{Characterization}

Raman spectra were obtained by a Renishaw inVia with a laser of $532 \mathrm{~nm}$ and $0.5 \%$ strength, samples were arranged on the silica plate. X-ray diffraction (XRD) patterns of the samples were recorded on a Rigaku D/MAX2550 diffractometer using $\mathrm{Cu} \mathrm{K} \alpha$ radiation of wavelength $1.5406 \AA$, typically run at a voltage of $40 \mathrm{kV}$ and current of $100 \mathrm{~mA}$. UV-visible absorbance spectra were achieved for the dry pressed disk samples using a Scan UV-Vis spectrophotometer (Varian, Cary 500) equipped with an integrating sphere assembly, using BaSO4 as a reflectance sample. Transmission electron microscopy (TEM) images were collected on a JEOL JEM 2010F, electron microscope operated at an acceleration voltage of $200 \mathrm{kV}$. By utilizing the Barrett-Joyner-Halenda (BJH) model, the pore volumes and pore size distributions were got from the adsorption branches of isotherms.

\section{Preparation of SBA-15}

Generally, $8.0 \mathrm{~g}$ P123 and $8.8 \mathrm{~g} \mathrm{KCl}$ were dissolved in $120 \mathrm{~mL}, 4 \mathrm{M}$ hydrochloric acid solution. After stirring at $38^{\circ} \mathrm{C}$ for $2 \mathrm{~h}, 18 \mathrm{~mL}$ TEOS was added into the solution. $2 \mathrm{~min}$ later, the solution was kept still for $24 \mathrm{~h}$. After that, the mixture was transferred into an autoclave and hydrothermally treated at $100{ }^{\circ} \mathrm{C}$ for $24 \mathrm{~h}$ to obtain as-made samples. Then the composites were filtered off and washed by ultrapure water and ethanol. In the end, the sample was calcined at $550{ }^{\circ} \mathrm{C}$ for $6 \mathrm{~h}$ to remove temples after drying at $60{ }^{\circ} \mathrm{C}$ in the vacuum.

\section{Preparation of Ag SBA-15}

First, 0.2 g SBA- 15 was dried by vacuum at $140{ }^{\circ} \mathrm{C}$ with the temperature increasing at $1{ }^{\circ} \mathrm{C} / \mathrm{min}$ to remove physically adsorbed water. Then the sample was dispersed in $20 \mathrm{~mL}$ of n-hexane. $10 \mathrm{~min}$ later, $0.2 \mathrm{~mL}, 1.0 \mathrm{~mol} / \mathrm{L}$ $\mathrm{AgNO}_{3}$ was added into the solution and stirred for $4 \mathrm{~h}$ in the dark. After stirring, the composites were filtered off and dried at $80{ }^{\circ} \mathrm{C}$ to remove the liquid. For the synthesis of $\mathrm{Ag} \mathrm{SBA}-15 / \mathrm{NW}$, the powder sample was calcined at $350{ }^{\circ} \mathrm{C}$ for $2 \mathrm{~h}$ at an increasing rate of $2{ }^{\circ} \mathrm{C} / \mathrm{min}$. Ag SBA-15/NS was formed by further calcining Ag SBA-15/NW 
at $550{ }^{\circ} \mathrm{C}$ for another $2 \mathrm{~h}$ or directly calcining the impregnated powder at $550{ }^{\circ} \mathrm{C}$ for $2 \mathrm{~h}$.

\section{Preparation of Ag SBA-15 film and Raman detection}

$10 \mathrm{mg}$ Ag SBA-15/NS or Ag SBA-15/NW were dispersed in $1 \mathrm{~mL}$ ethanol, and sonicated to make it totally dispersed, which was then spin-coated on a glass slide $(38 \mathrm{~mm} \times 24 \mathrm{~mm})$. Then the slide was divided into 4 parts and dropped by $10 \mu \mathrm{L}$ methylene blue (MB) solution with different concentrations before Raman detection.

\section{Preparation of Ag-AgCl SBA-15/NW and photocatalytic degradation of MB}

Ag SBA-15/NW was transformed to $\mathrm{Ag} @ \mathrm{AgCl}$ SBA-15/NW by dropwise adding excessive amount of $\mathrm{FeCl}_{3}$ water solution on the slide or just immersing the slide into the $\mathrm{FeCl}_{3}$ solution to achieve most transformation efficiency from $\mathrm{Ag}$ to $\mathrm{AgCl} .2 * 10^{-5} \mathrm{M}$ of $\mathrm{MB}$ solution was used for the study about the recyclable detection. The substrate adsorbed with $\mathrm{MB}$ molecules was illuminated for $10 \mathrm{~min}$ by a simulated solar source equipped with a $300 \mathrm{~W}$ Xenon lamp for (AM 1.5). The re-adsorption was carried out after MB was completely photocatalytically degraded.

\section{Photocatalytic degradation of MB in solution}

$0.10 \mathrm{~g}$ of $\mathrm{Ag} \mathrm{SBA}-15 / \mathrm{NW}$ after reacted with $\mathrm{FeCl}_{3}$ was dispersed in the $8.0 \mathrm{~mL}, 1 * 10^{-5} \mathrm{~mol} / \mathrm{L} \mathrm{MB}$ solution. After $0.5 \mathrm{~h}$ dark adsorption, the solution was illuminated for $20 \mathrm{~min}$ by a simulated solar source equipped with a $300 \mathrm{~W}$ Xenon lamp for (AM 1.5). Besides the Raman spectroscopy, UV-Vis absorption spectroscopy was also used for the degradation analysis.

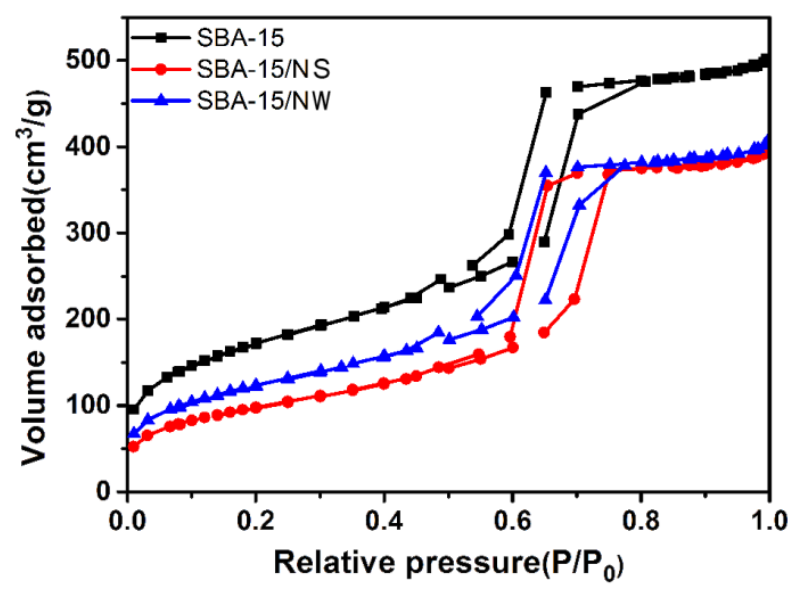

Fiugre. S1 Nitrogen adsorption-desorption isotherms of SBA-15, Ag SBA-15/NS and Ag SBA-15/NW. 


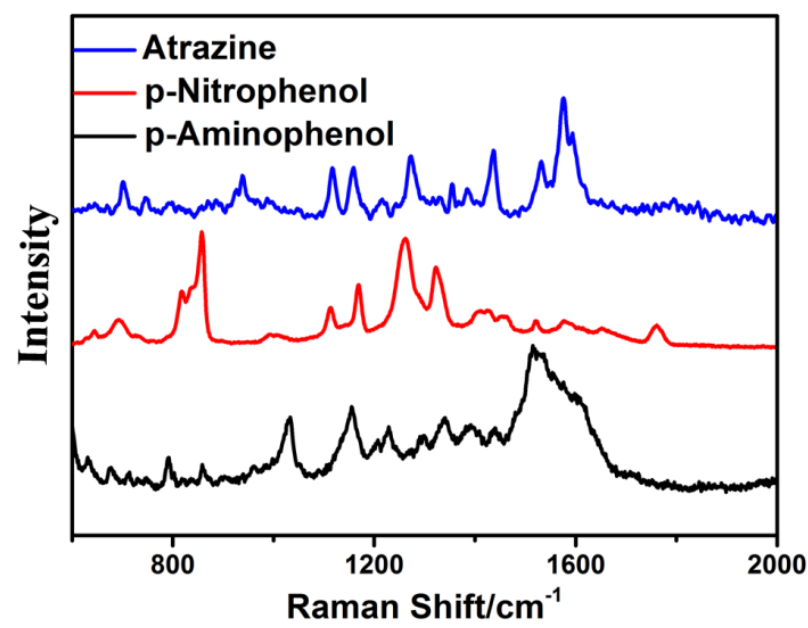

Figure. S2 Raman spectrum of atrazine $\left(1 * 10^{-5} \mathrm{~mol} / \mathrm{L}\right)$, p-nitrophenol $\left(1 * 10^{-4} \mathrm{~mol} / \mathrm{L}\right)$ and p-aminophenol $\left(1 * 10^{-4} \mathrm{~mol} / \mathrm{L}\right)$.

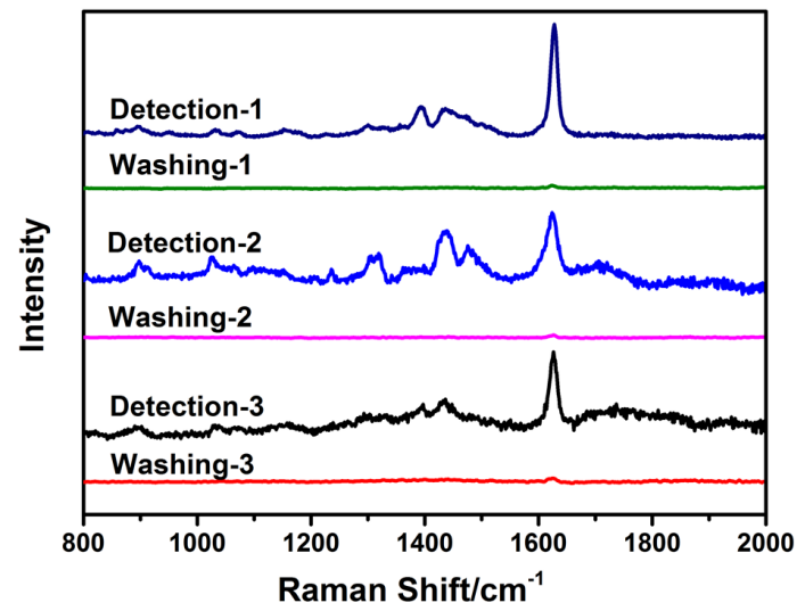

Figure. S3 Recycling SERS detection of $10^{-5} \mathrm{M}$ MB on Ag SBA-15/NW by washing with ethanol.

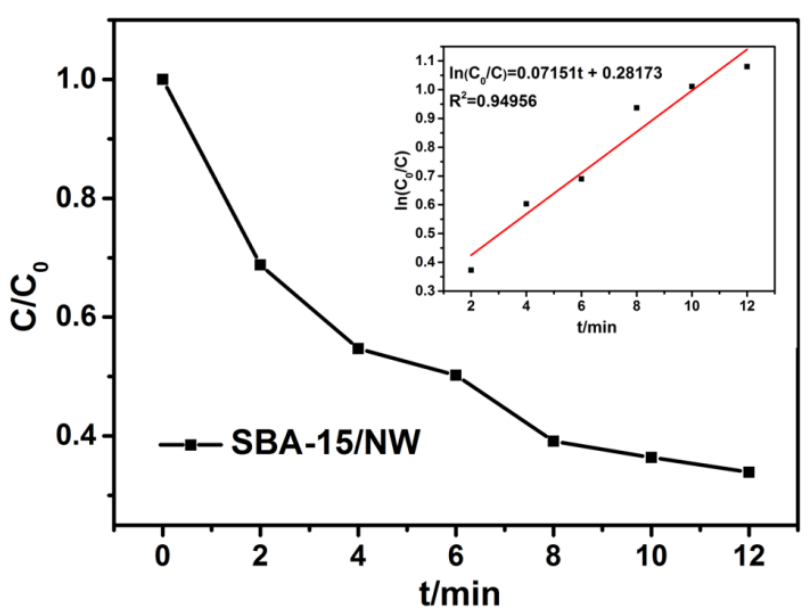


Figure. S4 Photocatalytic degradation curve of MB plotted from UV-Vis absorption spectra and the degradation kinetics curve (Inset). The degradation can be finished within $20 \mathrm{~min}$, which is longer than that observed from SERS detection system. The difference should be caused by the difference between suspension and film photocatalysis systems.

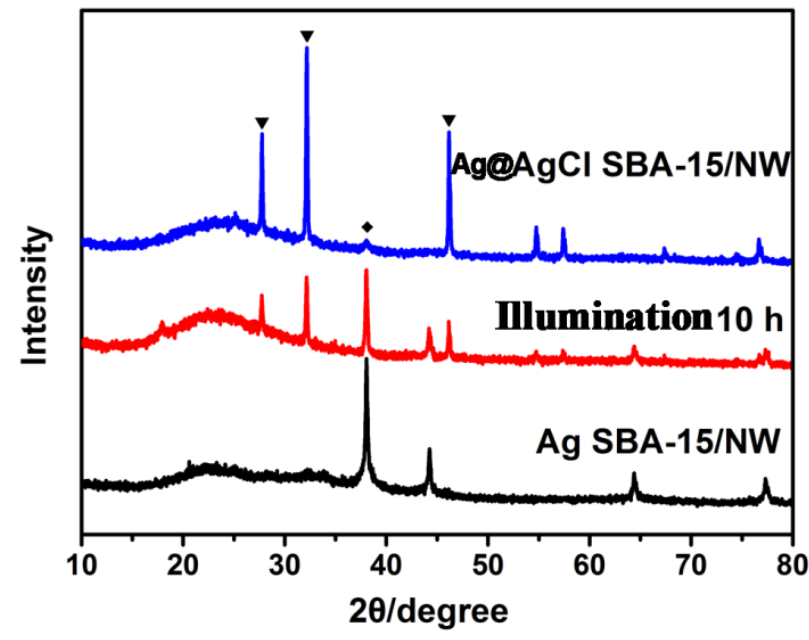

Figure. S5 Wide-angle XRD patterns of Ag SBA-15/NW (black), Ag@AgCl SBA-15/NW before (blue) and after photoillumination (red). 